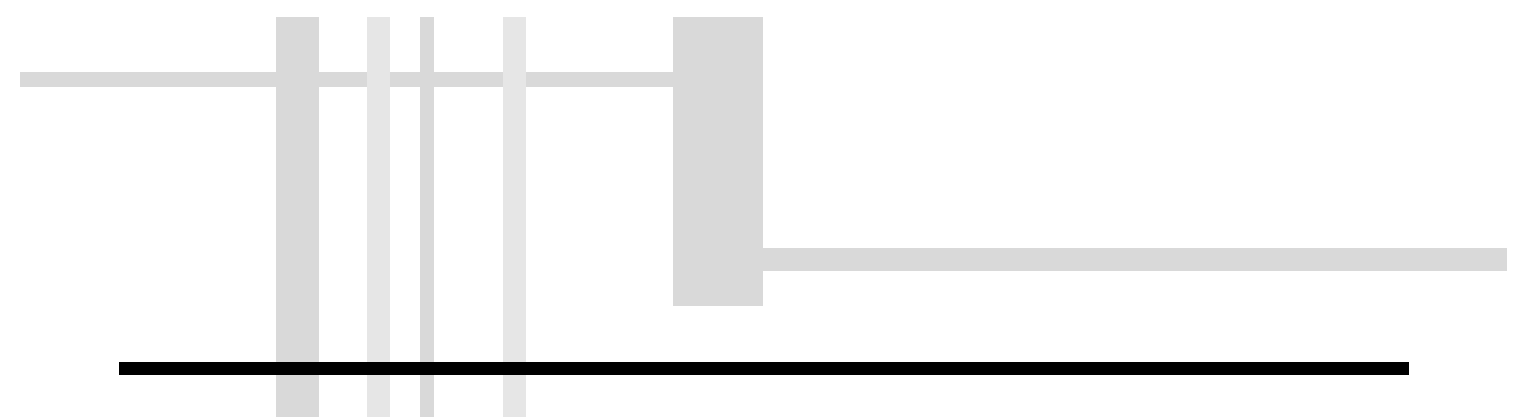

\title{
Descripción fenomenológica de la ecolocalización, imágenes a partir de sonidos
}

Jully Peña

jully.pena@uptc.edu.co

\section{Grupo de Física de Materiales (GFM) \\ Facultad de Ciencias Básicas \\ Escuela de Física}

\section{Resumen}

Muchos animales utilizan el sonido como herramienta de ubicación y supervivencia, por esta razón sus sistemas auditivos han evolucionado eficazmente, asegurando su conservación en la naturaleza. Uno de los procesos más interesantes desarrollados por estos sistemas biológicos es la ecolocalización, fenómeno consistente en la ubicación y reconocimiento del medio ambiente a través del análisis de ondas sonoras de alta frecuencia y que ha alcanzado su máxima perfección, en los murciélagos. Aquí, este fenómeno es abordado en su descripción fenomenológica desde el punto de vista físico en cuanto al estudio de las ondas mecánicas y biológico a partir de la recepción y análisis de sonidos en estos animales.

Palabras clave: ecolocalización, sonido, sistema auditivo.

\section{Introducción}

El sonido es un fenómeno ondulatorio cuyas características físicas son aprovechadas por los sistemas sensoriales de los seres vivos como medio de comunicación; sin embargo, en algunos animales la percepción de los sonidos se ha desarrollado alcanzando grados de utilidad y sofisticación que aventajan en sumo grado a los sentidos del ser humano. Los sistemas biológicos son por lo general susceptibles a la interacción con ondas sonoras de baja frecuencia (infrasonidos), animales que utilizan esta situación son, por ejemplo, los tigres, que hacen uso de infrasonidos ligados al rugido, para confundir a sus presas o atacantes; así mismo, los elefantes utilizan estas señales para comunicarse a grandes distancias (que pueden llegar a ser kilómetros) enviando 
infrasonidos por el aire y el suelo. Por otro lado, ondas sonoras de alta frecuencia son utilizadas por los murciélagos, en estos cobran la mayor importancia y utilidad, pues ellos dependen casi totalmente del sonido para ubicarse y cazar, utilizando en esto el fenómeno físico extraordinario de la ecolocalización.

\section{Desarrollo}

"La ecolocalización es un proceso físico consistente en la emisión de pulsos sónicos de alta frecuencia por parte de un animal, este los recibe y analiza en forma de reflexiones sonoras o ecos para formarse imágenes mentales en 3D del espacio que lo rodea" (Altringham, 1996), esta herramienta hace uso de fenómenos físicos asociados con las ondas como la reflexión, refracción y el efecto doppler.

La reflexión es un fenómeno ondulatorio relacionado con características físicas del sonido, como su frecuencia y longitud de onda, se produce cuando una onda incide sobre un objeto y se devuelve al no poder atravesarlo. Si el tamaño del objeto es pequeño, comparado con la longitud de onda, esta lo rodeará; de lo contrario la onda se reflejará generando un eco (Crawford, 1976), este eco es recogido y procesado por los animales que utilizan ecolocalización y de este pueden obtener información como la distancia a la que está un obstáculo, su tamaño, forma y textura, esto lo hacen midiendo el tiempo de diferencia entre el sonido original y su eco y el cambio en frecuencia y amplitud del mismo. El sofisticado sistema auditivo-neuronal del murciélago le permite recoger y analizar esos reflejos para orientarse y cazar con efectividad.

Los murciélagos emiten sonidos en un rango de frecuencias muy amplio, que recorre desde los sonidos audibles para los humanos, durante la comunicación con otros murciélagos, hasta ultrasonidos (sonidos de altísima frecuencia, por encima de $20 \mathrm{kHz}$ ), usados en la ecolocalización (Altringham, 1996); cuyas altas frecuencias garantizan cortas longitudes de onda (desde unos tres milímetros hasta algunos micrómetros) capaces de reflejarse en presencia de objetos pequeñísimos del tamaño de un mosco y del grosor de un cabello humano.

Si se encuentran ondas cuyas frecuencias son similares e interactúan una con la otra, se modifican las características originales de ambas, este fenómeno se conoce como interferencia; en la ecolocalización se evita al máximo que se presente este fenómeno por la complejidad que implicaría para el animal la clasificación de ondas modificadas de este modo y no por los objetos presentes en el ambiente. Las altas frecuencias sirven para evitar la interferencia, ya que hay pocos sonidos tan altos en la naturaleza, además las ondas de estas frecuencias no viajan lejos antes de reflejarse y no alertan a posibles depredadores, pues no son capaces de oír estos sonidos (Neuweiler, 2000).

Los murciélagos producen los ultrasonidos en la laringe y controlan su frecuencia a través de ajustes de la tensión en las cuerdas vocales. Las ondas sonoras se producen como consecuencia de una compresión en el aire, la cual genera un enrarecimiento en 
el aire circundante, y este a su vez otra compresión, así se propaga la onda y la velocidad con que lo hace depende de características del medio, como densidad, temperatura y presión. Estas ondas chocan con los diferentes objetos y regresan en una dirección determinada de acuerdo con la ley de Snell de la reflexión que, para el caso del murciélago, el cual está de frente al objeto, es la misma dirección de emisión; la comparación de la onda enviada con la recibida proporciona la información necesaria para trazar un mapa mental del medio.

Las orejas de los murciélagos tienen movimiento independiente y pabellones auditivos grandes, para enfocar la onda hacia el tímpano y aumentar la presión en este, las vibraciones pasan por huesos del canal auditivo que finalmente generan señales eléctricas hacia el cerebro, el cual posee dos clases de neuronas utilizadas en ecolocación: una para activar los músculos que producen el sonido y otra para procesar los ecos: estas últimas están distribuidas por toda la corteza cerebral y se subdividen con el fin analizar los ecos provenientes a tiempos diferentes, es decir, cada zona del cerebro analiza ecos con determinado tiempo de retraso luego de la señal emitida (Neuweiler, 2000).

Estos mamíferos emiten sonidos de ecolocalización en pulsos que son diferentes para las diferentes especies de murciélagos, en algunos estos pulsos son de frecuencia modulada (FM) y en otros de frecuencia constante (FC) (Altringham, 1996); sin embargo, suelen presentarse juntos, aprovechando las ventajas que cada uno ofrece.

Las ondas de frecuencia modulada tienen pulsos no constantes, es decir, su frecuencia varía en rangos de $30 \mathrm{kHz}$ a $60 \mathrm{kHz}$ con una duración de $0.2 \mathrm{~ms}$ a $5.0 \mathrm{~ms}$, esto para evitar que la onda regrese antes que el pulso termine de ser emitido (mientras es enviado un sonido, el canal auditivo está cerrado para evitar el daño a órganos sensibles a sonidos muy fuertes) (Neuweiler, 2000); los pulsos de FM se caracterizan por empezar con frecuencias bajas en las fases de búsqueda y ubicación, y un aumento gradual de la misma cuando el animal se acerca a la presa, cuanto más cerca esté de ella el murciélago necesita más exactitud en su ubicación, con el aumento de frecuencia evita que el sonido se desvíe por su baja longitud de onda, así tendrá mayor poder de penetración, lo cual da indicios sobre la composición interna del objeto próximo, de esta manera, el murciélago varía las frecuencias para determinar posición, velocidad, tamaño, forma y textura del blanco.

Por el contrario, los pulsos de FC mantienen la misma frecuencia durante la emisión del pulso, estos duran de $10 \mathrm{~ms}$ a $50 \mathrm{~ms}$ y sus frecuencias son un poco menores, por lo que las ondas cubren distancias mayores y no se atenúan tanto en el aire, por esta razón se usan en la fase de búsqueda; no obstante, estos no proporcionan información acerca de la estructura interna de la presa por lo que son combinados con pulsos de FM, es decir, luego de la fase de búsqueda se introducen los armónicos (frecuencias que son múltiplos de la frecuencia natural de oscilación de las cuerdas vocales del murciélago) para aumentar la frecuencia (Neuweiler, 2000). 
Como en las llamadas FC los pulsos no cambian de frecuencia, los murciélagos no pueden determinar la posición o velocidad del blanco, por la diferencia en frecuencia en la onda reflejada en sí misma; para el cálculo de estos parámetros hacen uso del efecto doppler, este es un fenómeno físico consistente en el cambio de la frecuencia de una onda percibida por un observador, debido al movimiento relativo entre fuente y receptor (Franco, S.F.). En el caso de los murciélagos, estos se mueven con la misma velocidad, ya que el animal cumple los dos papeles. Cuando el murciélago está en reposo y la presa se mueve, la frecuencia de la onda reflejada percibida por el murciélago es menor si la presa se aleja y mayor si esta se acerca, así puede conocer la posición y la velocidad determinando qué tanto está aumentando o disminuyendo la frecuencia percibida, es decir, cuánto está variando el tiempo de retorno de la onda reflejada.

Generalmente los murciélagos no están en reposo, sino que se mueven tras la presa; en este caso una señal que es emitida llega a la presa en un tiempo $t_{1}$ y se refleja volviendo al emisor en un tiempo $t_{11}$ que depende de la velocidad con la que se mueva el murciélago con respecto al blanco, dado que este será mayor si la velocidad del murciélago es menor y menor si este se mueve más rápido. Cuando se emite una segunda señal, esta de nuevo da en el blanco en un tiempo $t_{2}$ y llega al murciélago en $t_{22}$, así el periodo medido por el murciélago es la diferencia entre los tiempos medidos $t_{22} y t_{11}$, y la diferencia de la frecuencia será, por supuesto, el inverso de ese periodo, con esa diferencia comparada con la frecuencia de emisión del sonido, el murciélago puede ubicar a su presa en posición y velocidad sin tener que cambiar la frecuencia durante los pulsos; sin embargo, los murciélagos procuran cambiarla para que la frecuencia percibida de la onda reflejada esté alrededor de los $82 \mathrm{kHz}$ pues sus oídos están "afinados" para ser más sensibles a sonidos de esta frecuencia (Neuweiler, 2000). La combinación efectiva de estos dos tipos de llamada garantiza la efectividad en la caza, consecución de alimento y ubicación en absoluta ausencia de luz.

Se conocen dos mecanismos por los que los murciélagos no confunden sus sonidos con los de otros: uno consiste en suprimir del primero los armónicos de sus cuerdas vocales alrededor del $1 \%$ de su energía, con esto disminuye la amplitud y el eco se hace tan débil que no es capaz de abrir los canales auditivos de otros murciélagos; el otro método es un complicado sistema neuronal que durante pulsos combinados de FC/FM sólo procesa pulsos reflejados de FM precedidos de pulsos FC con la apropiada diferencia temporal, así el murciélago ignora pulsos de rangos temporales diferentes porque "conoce" los suyos y el tiempo que debe haber entre ellos; además, cada murciélago tiene un timbre con pulsos y frecuencias propios tal, como cada persona tiene una voz propia diferente a las demás.

Hasta ahora no se ha comprobado que al igual que las ballenas los murciélagos posean algún sistema sensorial magnético, por lo que se asume que aun en viajes largos estos usan la ecolocalización para volver a sus hábitat por el reconocimiento amplio en 3D de los objetos familiares a la cueva de cada uno, esto pueden hacerlo aunque haya medios diferentes por los que deban atravesar, pudiendo también reconocer e interceptar objetos 
en el agua, para esto utilizan otro fenómeno típicamente ondulatorio, la refracción, basado en la diferencia de la velocidad de propagación en medios diferentes, este cambio de velocidad cambia también la dirección, así la onda refractada atraviesa el medio pero se desvía, los murciélagos son capaces de percibir ese cambio de dirección y velocidad además de la diferencia de texturas entre el agua y la tierra.

El fenómeno de la ecolocalización en murciélagos ha sido estudiado por centros de investigación en Biología y Física de todo el mundo desde antes de la Segunda Guerra Mundial, pero a pesar de eso son muchos los mecanismos y procesos implicados que son desconocidos por la ciencia y son objeto de estudio en la actualidad.

\section{Conclusiones}

La ecolocalización puede entenderse como un sistema de percepción sensorial dependiente de las propiedades físicas de los fenómenos ondulatorios, en particular de la reflexión y refracción de las ondas sonoras, además del efecto doppler estos les permite a ciertos animales adecuarse al medio obteniendo de este información detallada para su supervivencia en el mismo; aunque no todos los procesos biológicos pueden ser explicados por la Física, estos son tomados como base para la elaboración de sistemas artificiales que los imiten aunque por el momento se encuentren ante un abismo de desventaja con los sistemas naturales, los cuales son el resultado de miles de años de evolución.

En los seres vivos los sistemas físicos y biológicos se combinan dando lugar a complejos procesos que son base del estudio de la mayoría de las ciencias.

\section{Referencias bibliográficas}

Altringham, J. (1996). Bats, Biology and Behavior. New York: Oxford University.

Crawford, F. (1976). Ondas. España: Reverté.

Franco, A. Física con ordenador. S.F.

Neuweiler, G. (2000). The Biology of Bats. New York: Oxford University. 